\title{
Performance Benchmark of Si IGBTs vs. SiC MOSFETs in Small-Scale Wind Energy Conversion Systems
}

\author{
Abdallah Hussein, Alberto Castellazzi, Pat Wheeler, Christian Klumpner \\ The University of Nottingham \\ Power Electronics, Machines and Control (PEMC) Group \\ E-mail:eexash@nottingham.ac.uk
}

\begin{abstract}
Modern power electronics devices based on $\mathrm{SiC}$ power MOSFETs technology become more demanding in the last few years. They show better performance over Si-IGBTs on renewable energy power conversion systems due to their higher switching frequency, higher temperature capability, higher power density and higher reliability. This paper presents a benchmarking of SiC-MOSFET and Si-IGBT power devices with the voltage rating of $1200 \mathrm{~V}$ in 2-Level Full-Bridge (2L-FB) inverter for $10 \mathrm{~kW}$ small scale wind turbine. By simulation, the inverter performance is evaluated in the presence of the wind speed distribution profile and the reference switching frequency value for $\mathrm{SiC}$ devices in this topology at this power level is determined. The results show that the $\mathrm{SiC}$ solution can improve the efficiency, save energy and reduce the size and cost due to high switching frequency and temperature capabilities.
\end{abstract}

\section{INTRODUCTION}

Wide bandgap devices, such as Silicon Carbide (SiC) exhibit advantages over Silicon ( $\mathrm{Si}$ ) for power semiconductor applications: higher switching frequency, higher temperature capability, higher power density and higher reliability[1-3]. Nowadays, the commercially available power MOSFETs that satisfies the above benefits are with voltage ratings of 400 , $650,900,1200$ and $1700 \mathrm{~V}$ for both discrete and module packages, and Schottky diodes with ratings up to $8 \mathrm{KV}$ [2]. This recent commercialization is expected to have the potential to deliver revolutionary impact on power electronics industry in the future. According to the availability of $\mathrm{SiC}$ power MOSFETs on the markets; the main areas that can be utilized by this technology are PV inverter, speed drives, pumps and automotive [3], as well as small-scale wind turbines.

$\mathrm{SiC}$ technology is generally favored beyond the capabilities offered by $\mathrm{Si}$ devices for use in power conversion applications. Firstly, due to the relatively lower switching transitions of $\mathrm{SiC}$ devices as a result of the reliance on drift current, the switching frequency can be increased, thus aiming to reduce the size and the cost of the passive components and improve system dynamics. Secondly, because of the higher thermal capability and very good thermal stability of $\mathrm{SiC}$ devices due to a wider energy bandgap (nearly three-fold values) compared to $\mathrm{Si}$, this resulting in reducing the converter cooling requirements and pushing the converter to operate in a harsh environment, where Si devices could not perform well. Thirdly, due to the higher critical electric field, this lead to maximizing the doping level and minimizing the thickness of the device for a given blocking voltage capability, this results in lower on-state conduction losses. Finally, the thermal resistance of $\mathrm{SiC}$ devices is smaller than that of Si (typically three times), this aiming to increase the power density of the device or decrease the device operational temperature. However, $\mathrm{SiC}$ technology shows limitation to the maximum exploitation of the potential benefits of this technology due to the packaging, particularly in terms of high temperature feature, power density, parasitic inductance and electro-magnetic noise [1-4].

Small-scale wind turbines are mainly used to supply electricity to homes, farms, and small business in remote areas. They differ from their large-scale wind turbine in their rating, size, generator type, and the topology of the power electronics conversion system [5, 6]. For small-scale wind conversion system in the power ranges up to hundred $\mathrm{kW}$, it is a trend to use a PMSG in industry applications especially for a directly driven wind turbine with benefits of size and weight reduction. As there is no reactive power needed, the conversion system is a simple 3-phase diode rectifier with dcdc boost converter connected to 2-level full bridge Si IGBT PWM inverter as shown in Fig. 1 [6-9].

Application of $\mathrm{SiC}$ devices in small-scale wind conversion system has been discussed in literature. In [10],designed a push-pull DC/DC converter achieved 93\% peak efficiency developed for the $\mathrm{HF}$ isolation stage for a $1.3 \mathrm{~kW}$ and operating frequency of $100 \mathrm{kHz}$ for PMSG-based wind turbines. However, no study has yet demonstrated the benefits of utilizing $\mathrm{SiC}$ in $2 \mathrm{~L}-\mathrm{FB}$ grid-side inverter based on $1200 \mathrm{~V}$ SiC-MOSFETs module to improve the efficiency and achieve higher switching frequencies and power densities due to reducing the sizes of the passive elements and heatsink, neither optimized the heatsink design based on the wind speed distribution profile (i.e., in most works, the heatsink is designed based on the maximum operating output power). In

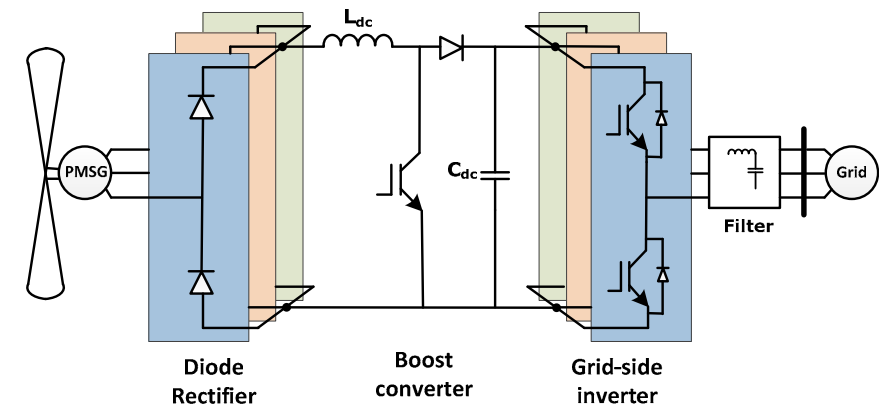

Fig. 1. Small scale wind turbine power conversion system. 
addition, this paper addresses the choice of the reference switching frequency value for $\mathrm{SiC}$ devices in this topology at this power level by some optimum compromise between the converter efficiency and volume. In this work, the performance analysis between SiC-MOSFETs and Si-IGBTs rated at $1200 \mathrm{~V}$ blocking voltage in $10 \mathrm{~kW}$ small-scale wind turbine is done based on a 2-level three phase grid-side inverter. Actually, the comparison is made between a threephase bridge MOSFET power module rated at $1200 \mathrm{~V} / 20 \mathrm{~A}$ (CCS020M12CM2 from CREE) and a three-phase bridge IGBT power module rated 1200V/25A (FS25R12W1T4_B11 from Infineon). This paper investigates the efficiency at different wind speed and a wide range of switching frequency and junction temperature in order to fully evaluate of $\mathrm{SiC}$ and $\mathrm{Si}$ devices. Here, the wind speed distribution profile is considered in the evaluation and design, and a critical discussion is presented.

This paper is organized as follows: description of the 2-level Full Bridge Inverter is presented in Section II; inverter power losses are modeled in section III; the inverter heatsink, DC-link and output filter are analyzed in Sections IV; the distribution and probability of wind speed are analyzed in Section V, the simulation and discussion are presented in section VI and, finally, the conclusion is discussed.

\section{DESCRIPTION OF THE 2-LEVEL FULL BRIDGE INVERTER}

Pulse width modulation voltage source inverter with twolevel output voltage is one of the interesting candidates for the wind turbine. This topology is chosen to compare the influence of $1200 \mathrm{~V} \mathrm{SiC}$ devices based on a six-pack (three phase) module on the overall converter performance. As shown in Fig. 2., the wind turbine model under the maximum power point tracking is simplified by a current source connected in parallel with the DC link capacitor of the gridside inverter. The input signal of the current source is [11]:

$$
I_{w}=P_{w, o p t} / V_{d c} \text {. }
$$

Where, $P_{w, o p t}$ is the optimal wind power and $V_{d c}$ is the DC link voltage of the converter.

Here, the optimal output power of a $10 \mathrm{~kW}$ commercial smallscale wind turbine as shown in Fig. 3 is considered [12].

In this study, the power rating of the inverter is $12 \mathrm{~kW}$, which is a representative figure for a commercial small-scale wind application and LC filter to minimize the output current harmonics.

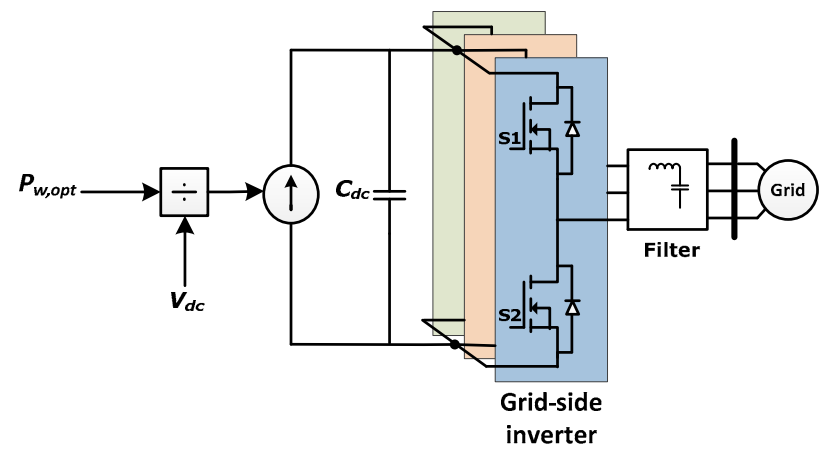

Fig. 2. Two-Level Full Bride (2L-FB) inverter.

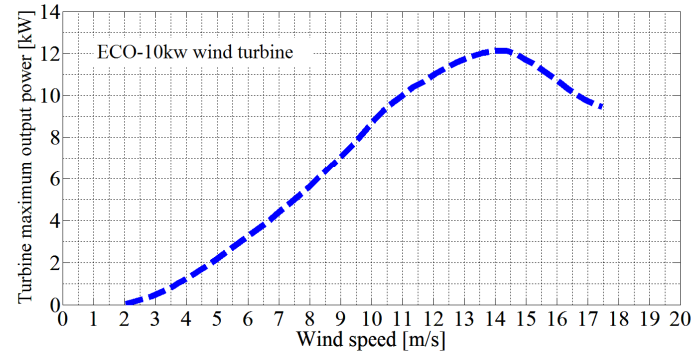

Fig. 3. ECO-10kW wind turbine maximum output power.

\section{INVERTER POWER LOSS MODELING}

\section{A. SiC Converter}

The on-state voltage of SiC-based MOSFET and Schottky diode are calculated as follows [13]:

$$
\begin{gathered}
V_{S}=I_{S} R_{S, \text { on. }} \\
V_{D}=V_{D, \text { on }}+I_{D} R_{D, \text { on }} .
\end{gathered}
$$

Where $I_{S}$ and $I_{D}[\mathrm{~A}]$ are the conduction current through $\mathrm{SiC}$ MOSFET and Schottky diode, respectively, $R_{S, \text { on }}$ and $R_{D, \text { on }}[\Omega]$ are on-state resistance for SiC MOSFET and Schottky diode, respectively, and $V_{D, \text { on }}[\mathrm{V}]$ is the Schottky diode on-state voltage when $I_{D}=0$.

The on-state resistances for $\mathrm{SiC}$ MOSFET switch as a function of the semiconductor junction temperature are as follows [14]:

$$
R_{S, o n}=a_{2} T_{j}^{2}+a_{1} T_{j}+a_{0}[\mathrm{~m} \Omega] .
$$

Where $a_{0}, a_{1}$ and $a_{2}$ are coefficients derived from MOSFET on-state resistance information provided in the datasheet.

The on-state voltage and resistance of Schottky diode depend on the junction temperature as follows [15]:

$$
\begin{gathered}
V_{D, \text { on }}=\alpha T_{j}+V_{D 0 .} \\
R_{D, \text { on }}=\beta T_{j}+R_{D 0}[\mathrm{~m} \Omega] .
\end{gathered}
$$

Where $\alpha, \beta, \quad V_{D 0}$ and $R_{D, \text { on }}$ are extrapolated from the Schottky diode forward characteristic data provided by the manufacturer.

The values of conduction losses for SiC MOSFET and Schottky diode are calculated as follows [14]:

$$
\begin{gathered}
P_{S, \text { con }}=I^{2}(1 / 8+(1 / 3 \pi) M \cos \varphi) \times R_{S, \text { on }} \\
P_{D, \text { cond }}=I(1 / 2 \pi-(1 / 8) M \cos \varphi) \times V_{D, \text { on }}+ \\
I^{2}(1 / 8-(1 / 3 \pi) M \cos \varphi) \times R_{D, \text { on } .}
\end{gathered}
$$

Where $M$ is the modulation index, $I$ [A] is the peak of output phase current, $\varphi[\mathrm{rad}]$ is the current phase shift.

The switching losses for SiC MOSFET switch is as follows [16]:

$$
\begin{gathered}
P_{S, s w}=f_{s w}\left(V_{d c} / V_{d c r e f}\right)^{k v}\left(\left(2 b_{3} / 3 \pi\right) I^{3}+\left(b_{2} / 4\right) I^{2}+\left(b_{1} / \pi\right) I+\left(b_{0} / 2\right)\right) \times \\
\left(1+T C_{s w}\left(T_{j}-T_{j r e f}\right)\right) \times 10^{-6} .
\end{gathered}
$$

Where $b_{0}, b_{1}, b_{2}$ and $b_{3}$ are coefficients derived from MOSFET switching loss information provided in the datasheet, $k v$ is the exponent of voltage dependency (MOSFET=1.5 [17]) and $T C_{S w}$ is the temperature coefficient of switching losses (MOSFET $=0$, based on the fact that the change of switching energy losses of SiC MOSFET devices with temperature is negligible).

The tested $\mathrm{SiC}$ module has zero reverse recovery diode; therefore, the Schottky diode switching losses is neglected. 


\section{B. Si Converter}

The on-state voltage of Si-based IGBT and power diode are calculated as follows [17]:

$$
\begin{gathered}
V_{S}=V_{S, \text { on }}+I_{S} R_{S, \text { on }} . \\
V_{D}=V_{D, \text { on }}+I_{D} R_{D, \text { on }} .
\end{gathered}
$$

Where $I_{S}$ and $I_{D}$ are the conduction current through $\mathrm{Si}$ IGBT and power diode, respectively, $R_{S, \text { on }}$ and $R_{D, \text { on }}$ are onstate resistance for Si IGBT and power diode, respectively, and $V_{S, \text { on }}$ and $V_{D, o n}$ are the Si IGBT and power diode on-state voltage when $I_{S}=0$ and $I_{D}=0$ respectively.

The on-state voltage and resistance of Si IGBT switch depend on the semiconductor junction temperature as follows [18]:

$$
\begin{gathered}
V_{S, o n}=\gamma T_{j}+V_{S 0 .} . \\
R_{S, \text { on }}=a_{2} T_{j}^{2}+a_{1} T_{j}+a_{0}[\mathrm{~m} \Omega] .
\end{gathered}
$$

Where $\gamma, V_{S 0}, a_{0}, a_{1}$, and $a_{2}$ are extracted from IGBT forward characteristics information offered in the datasheet.

The temperature dependency of on-state voltage and resistance of Si power diode are as follows [18]:

$$
\begin{gathered}
V_{D, \text { on }}=\alpha T_{j}+V_{D 0 .} . \\
R_{D, \text { on }}=\beta T_{j}+R_{D 0}[\mathrm{~m} \Omega] .
\end{gathered}
$$

Where $\alpha, \beta, V_{D 0}$ and $R_{D, \text { on }}$ are extracted from Si power diode forward characteristic information provided in the datasheet.

The conduction losses for Si IGBT and power diode are calculated as follows [17]:

$$
\begin{gathered}
P_{S, \text { cond }}=I(1 / 2 \pi+(1 / 8) M \cos \varphi) \times V_{S, \text { on }}+ \\
I^{2}(1 / 8+(1 / 3 \pi) M \cos \varphi) \times R_{S, \text { on. }} \\
P_{D, \text { cond }}=I(1 / 2 \pi-(1 / 8) M \cos \varphi) \times V_{D, \text { on }}+ \\
I^{2}(1 / 8-(1 / 3 \pi) M \cos \varphi) \times R_{D, \text { on. }}
\end{gathered}
$$

The switching losses for Si IGBT switch and power diode are as follows [16]:

$$
\begin{gathered}
P_{S, s w}=f_{s w}\left(V_{d c} / V_{d c r e f}\right)^{k v}\left(\left(2 b_{3} / 3 \pi\right) I^{3}+\left(b_{2} / 4\right) I^{2}+\left(b_{1} / \pi\right) I+\left(b_{0} / 2\right)\right) \times \\
\left(1+T C_{s w}\left(T_{j}-T_{j r e f}\right)\right) \times 10^{-6} \\
P_{D, s w}=f_{s w}\left(V_{d c} / V_{d c r e f}\right)^{k v}\left(\left(2 c_{3} / 2 \pi\right) I^{3}+\left(c_{2} / 4\right) I^{2}+\left(c_{1} / \pi\right) I+\left(c_{0} / 2\right)\right) \times \\
\left(1+T C_{s w}\left(T_{j}-T_{j r e f}\right)\right) \times 10^{-6} .
\end{gathered}
$$

Where $b_{0}, b_{1}, b_{2}$, and $b_{3}$ are constants derived from IGBT switching losses data provided in the device datasheet, $c_{0}, c_{1}$, $c_{2}$, and $c_{3}$ are coefficients extracted from $\mathrm{Si}$ diode switching losses, $k v$ is the exponent of voltage dependency (IGBT=1 and Diode $=1$ [19]) and $T C_{s w}$ is the temperature coefficient of switching losses (IGBT $=0.004$ and Diode $=0.006$, which are derived from the energy switching losses information of $\mathrm{Si}$ IGBT and diode at different junction temperatures).

\section{INVERTER DESIGN AND VOLUME}

\section{A. Heat sink analysis}

The heatsink thermal resistance can be calculated by the maximum power to be dissipated at a specific heatsink temperature as follow [20]:

$$
R_{h a}=\left(T_{h}-T_{a}\right) / P_{t} .
$$

Where: $R_{h a}$ is the heatsink thermal resistance $\left[\mathrm{W} /{ }^{\circ} \mathrm{C}\right], T_{h}$ is the reference heatsink temperature (equal to $60^{\circ} \mathrm{C}$ for PV and wind energy applications), $T_{a}$ is the ambient temperature (chosen as $25^{\circ} \mathrm{C}$ ), and $P_{t}$ is the total semiconductor losses.

The thermal circuit for devices in 2-Level FB converter is shown in Fig. 4, where, $T_{j}$ is the junction temperature, $T_{c}$ is

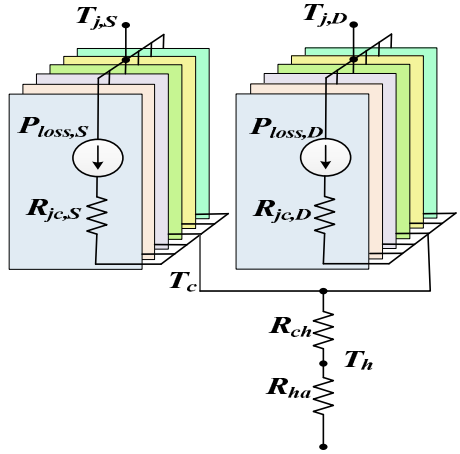

Fig. 4. Thermal circuit for Two-Level Full Bride (2L-FB) inverter.

the case temperature, $R_{j c}$ is the junction to case thermal resistance, and $R_{c h}$ is the case to heat sink thermal resistance.

The junction temperature for SiC MOSFET and Si IGBT devices can be calculated by (21) and (22), respectively:

$$
\begin{gathered}
T_{j, M O S F E T}=P_{\text {MOSFET }} R_{j c, M O S F E T} / 6+P_{t, S i C} R_{c h}+T_{h} . \\
T_{j, I G B T}=P_{I G B T} R_{j c, I G B T} / 6+P_{t, S i} R_{c h}+T_{h} .
\end{gathered}
$$

Where, $P_{\text {Mosfet }}$ is the total loss of Si C MOSFET switches, $P_{t, S i C}$ is the total loss of the SiC MOSFET switches and $\mathrm{SiC}$ Schottky diodes, $P_{I G B T}$ is the total loss of Si IGBT switches and $P_{t, S i}$ is the total loss of the Si IGBT switches and Si power diodes.

The volume of heat sink based on natural and forced cooling is derived by curve fitting of commercial extruded heatsink volume. Based on heatsink thermal resistance, the heatsink volume for natural and forced convection cooling can be calculated by (23) and (24), respectively:

$$
\begin{gathered}
\text { Vol }_{h s, \text { Natural }}=45110 R_{h a}{ }^{4}-15400 R_{h a}{ }^{3}+109910 R_{h a}{ }^{2}-47850 R_{h a}+8890 \\
\text { Vol } l_{h s, \text { Forced }}=117120 R_{h a^{2}}{ }^{2}-51950 R_{h a}+6670 .
\end{gathered}
$$

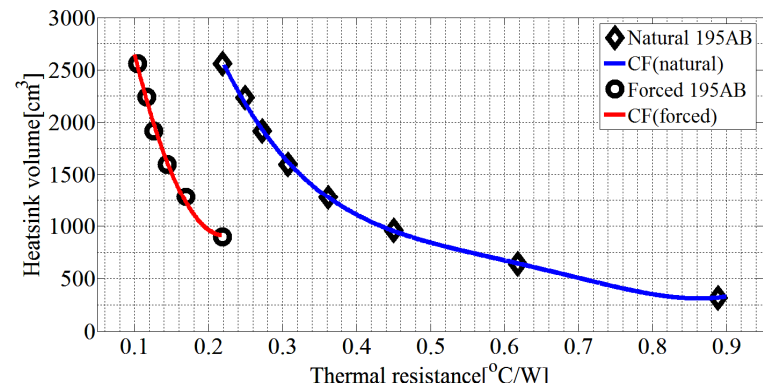

Fig. 5. Commercial naturally and forced cooled heat sink volumes versus thermal resistance.

\section{B. DC-link analysis}

The DC-link capacitor is to minimize the high switching frequency components of capacitor ripple current, as well as required for energy storage [21]. The DC-link capacitance by imposing a maximum current ripple to be carried by the capacitor and a peak-peak DC-link voltage ripple which is limited to $2 \%$ of the DC-link voltage is given as follows [22]:

$$
C_{d c}=I_{\text {cap }, R M S} / 2 \pi \times f_{s w} \times \Delta V_{d c}(\text { peak }) \text {. }
$$

The RMS capacitor ripple current is given by:

$$
I_{c a p, R M S}=I_{N, R M S} \sqrt{ }\left[2 M\left\{\sqrt{ } 3 / 4 \pi+\cos ^{2} \varphi(\sqrt{ } 3 / \pi-9 M / 16)\right\}\right]
$$

Where $M$ is the modulation index, $I_{N}$ is the output phase current and $\varphi$ is the current phase shift.

Power electronics conversion systems for the wind turbine are mainly based on a DC-link capacitor which occupies a significant part of the converter volume. The volume of the 
DC-link capacitor at different switching frequencies is derived by a curve fitting of the actual design based on MKP film capacitor series as shown in Fig. 6, and given by (27). Vol $_{C d c}=0.0898 \times 10^{-6} f s w^{2}-0.0102 f s w+431.78$

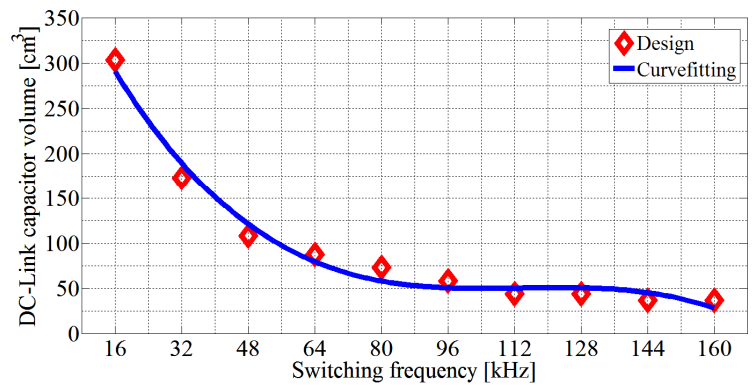

Fig. 6. DC-link volume at different switching frequency

\section{Output filter analysis}

The output filter of grid-connected inverter is to smooth the output ripple injected to the grid. The filter inductance of 2Level three phase inverter is given as follows [23]:

$$
L_{f}=V_{d c} / 8 f_{s w} \Delta I_{P P} \text {. }
$$

Where $V_{d c}[\mathrm{~V}]$ is the DC link voltage, $f_{s w}[\mathrm{~Hz}]$ is the switching frequency and $\Delta I_{P P}$ [A] is the peak to peak switching ripple current in the filter inductance which can be limited to $10 \%$ of the output rated current.

The value of the filter inductor becomes significant for 2level converters with power ratings of several kilowatts and above, thus, the inductor shares a valuable part of the converter volume. The inductor volume at different switching frequencies is derived based on the actual design and curve fitting of a standard $\mathrm{C}$ cut core as shown in Fig. 7 and given by (29).

$$
\text { Vol }_{L}=0.02475 \times 10^{-5} f_{s w}{ }^{2}-0.0308 f_{s w}+1527.852
$$

The capacitor for LC filter does not contribute significantly to the converter volume and hence is ignored in this study.

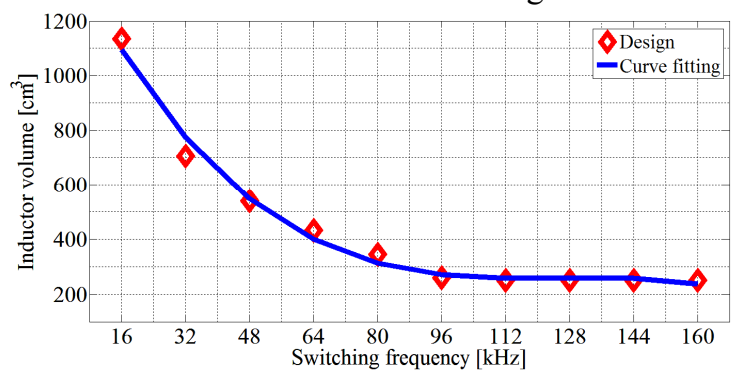

Fig. 7. Inductor volume at different switching frequency.

\section{WIND SPEED DisTRIBUTION}

The wind speed distribution can be characterized by a Weibull distribution [24]:

$$
\varphi_{U}=(k / C)(U / C)^{k-1} \exp \left[-(U / C)^{k}\right] .
$$

Where, $k$ [dimensionless] is the shape parameter and $C$ $[\mathrm{m} / \mathrm{s}]$ is the scale parameter. The scale parameter $C$ is related to the mean wind speed by the equation:

$$
C=2 U_{\text {mean }} / \sqrt{ } \pi \text {. }
$$

$U_{\text {mean }}[\mathrm{m} / \mathrm{s}]$ is the mean wind speed.

Fig. 8 shows the wind distribution in terms of hours per year for a typical shape parameter $k=2$, and a mean wind

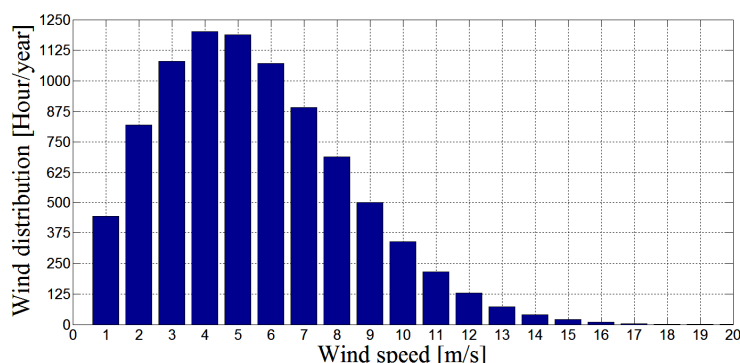

Fig. 8. Wind speed distribution.

speed $U_{\text {mean }}=5.5 \mathrm{~m} / \mathrm{s}$ at a tower height of $15 \mathrm{~m}$ for a chosen site. It is clear that the wind speed distribution is high at low wind speeds; on the other hand, the wind speed distribution is low at high wind speeds.

The probability of the wind speed is the integration the Weibull distribution, and it is given as below:

$$
\Phi(U)=\exp \left[-(U / C)^{k}\right]
$$

By considering wind turbine parameters of ECO- $10 \mathrm{~kW}$ [12], and as shown in Fig. 9, the turbine with rated speed of $11 \mathrm{~m} / \mathrm{s}$ generates at full power only $4 \%$ of the time and at the minimum wind speed of $3 \mathrm{~m} / \mathrm{s}$; the turbine generates power about $80 \%$ of the time.

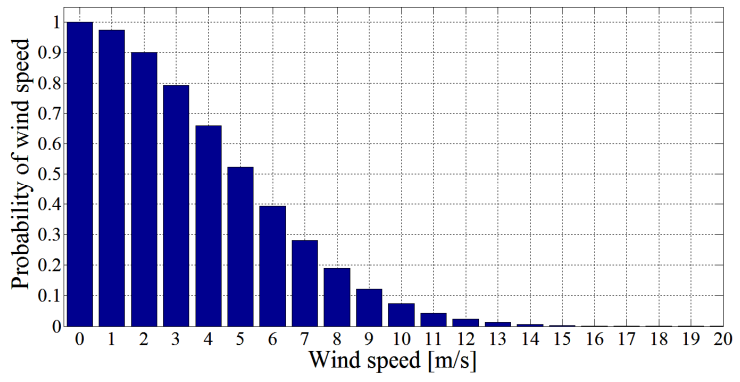

Fig. 9. Wind speed probability.

\section{SIMULATION AND DISCUSSION}

By simulating the converter over the range of wind speed from 3 to $17 \mathrm{~m} / \mathrm{s}$ at a switching frequency of $16 \mathrm{kHz}$, which is the reference value of Si-IGBT devices used for this topology at this power level. The converter cell efficiency for both SiC-MOSFET and Si-IGBT devices is shown in Fig. 10. Over the whole rang, $\mathrm{SiC}$ devices show higher efficiency than that of $\mathrm{Si}$, especially in the area where the wind distribution is high. Moreover, at the minimum wind speed operating range of $3 \mathrm{~m} / \mathrm{s}$ which has the chance of occurrence of $80 \%, \mathrm{SiC}$ devices have higher efficiency by a value of $5.7 \%$ than that of

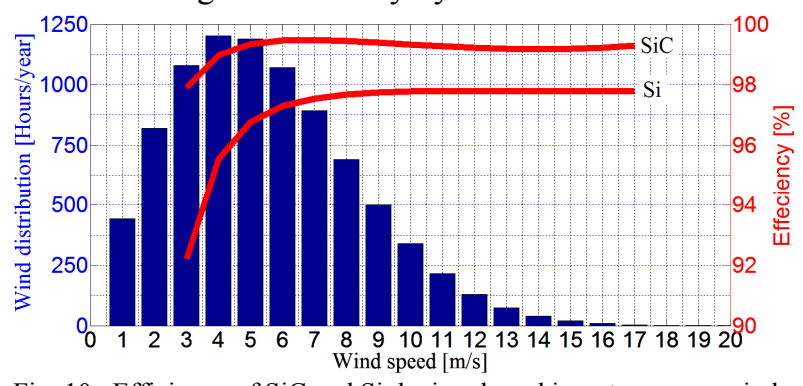

Fig. 10. Efficiency of $\mathrm{SiC}$ and $\mathrm{Si}$ devices based inverter versus wind speed at $60^{\circ} \mathrm{C}$ heatsink temperature and $16 \mathrm{kHz}$ switching frequency. 
Si devices. In addition, at the rated wind speed of $11 \mathrm{~m} / \mathrm{s}$, the efficiency of $\mathrm{SiC}$ is about $99.3 \%$ compared to $97.8 \%$ for $\mathrm{Si}$.

For grid-connected applications, by utilizing $\mathrm{SiC}$ devices solution instead of Si devices, the energy losses saving during a whole year is about $74.5 \%$ as shown in Fig. 11. By considering the existing UK infeed tariff for small-scale wind turbines $(8.54 \mathrm{p} / \mathrm{kWh})$, the total money saving is around $45.7 £ /$ year. Even the initial price of SiC-MOSFET module is higher than that of Si-IGBT module, money saving by utilizing $\mathrm{SiC}$ devices will balance the cost after two years of operation.

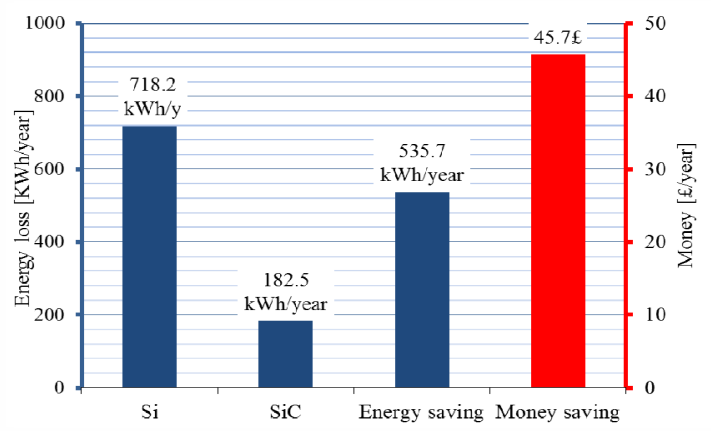

Fig. 11. Energy and money saving by utilizing SiC devices in smallscale wind turbine inverter.

When operating the converter at its maximum output power and a reference heatsink temperature of $60^{\circ} \mathrm{C}$ with a wide range of switch frequencies, the results in Fig. 12 show clearly that Si-IGBT devices can operate just on a narrow range of switching frequency due to a higher switching losses. In contrast with $\mathrm{SiC}$ devices, $\mathrm{SiC}$ works on a wider range of switching frequencies without significant loss of efficiency. Moreover, by increasing the switching frequency from $16 \mathrm{kHz}$ to $160 \mathrm{kHz}$, the efficiency is dropped more quickly at the rate of $1.6 \%$ per $16 \mathrm{kHz}$ for $\mathrm{Si}$ and by a slower rate of $0.1 \%$ per $16 \mathrm{kHz}$ for $\mathrm{SiC}$. This merit of SiC devices can lead to reduce the size and the cost of bulky filters and DClink capacitor in 2-level converters without losing a significant amount of efficiency. However, increasing the switching frequency leads to a larger heatsink volume as a result of an increase in converter cell power losses.

To identify some optimum compromise between the converter efficiency and volume, the best switching frequency is selected in order to obtain minimum converter volumes as shown in Fig 13. It is clear that the heatsink and the output filter volumes have the main contribution to the total converter volume and the minimum volume is realized

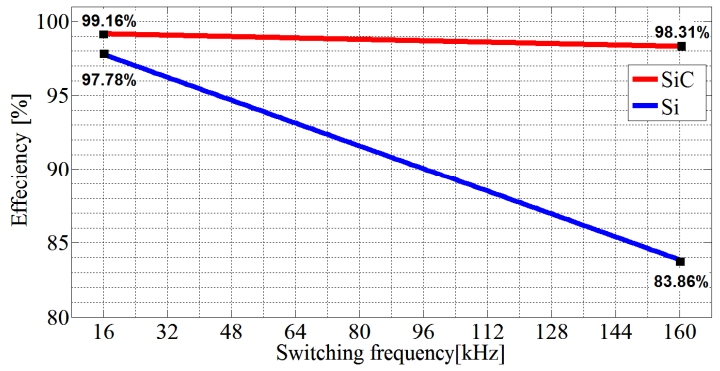

Fig. 12. Efficiency of $\mathrm{SiC}$ and $\mathrm{Si}$ versus switching frequency at the maximum output power and heatsink temperature of $60^{\circ} \mathrm{C}$.

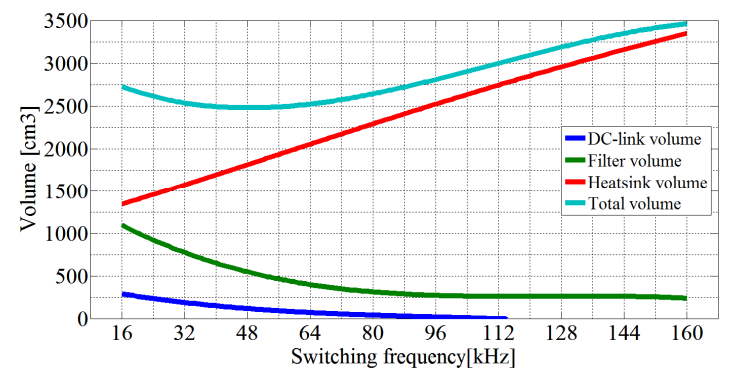

Fig. 13. Heatsink volume, filter volume and total volume for $\mathrm{SiC}$ devices based inverter at different switching frequencies.

at a switching frequency around $48 \mathrm{kHz}$ for the naturally cooled system. This value is considered to be the reference switching frequency for this topology at this power level. By switching $\mathrm{SiC}$ devices based converter at $48 \mathrm{kHz}$, the cell efficiency is about $98.9 \%$ and still over the efficiency of $\mathrm{Si}$ devices switched at $16 \mathrm{kHz}$ by amount of $1.1 \%$. In addition, this leads to reduce the output filter by a factor of 2.1 and the DC-link capacitor volume by 2.8 times and, therefore, higher power density.

By simulating the converter at the maximum wind turbine output power and converter switching frequency of $16 \mathrm{kHz}$ for both $\mathrm{Si}$ and $\mathrm{SiC}$ with different junction temperatures from $25^{\circ} \mathrm{C}$ to $150^{\circ} \mathrm{C}$. The results show higher temperature capability of $\mathrm{SiC}$ devices when compared with $\mathrm{Si}$ devices. Moreover, as shown in Fig. 14, the SiC devices show 0.46\% drop in efficiency which is much smaller than that of $\mathrm{Si}$ devices which show $1.3 \%$ drop in efficiency in the tested temperature range. In addition, it is obvious clearly that at the limited junction temperature of $150^{\circ} \mathrm{C}$, the $\mathrm{SiC}$ devices have higher efficiency of $1.7 \%$ than that of $\mathrm{Si}$ devices.

Due to the $\mathrm{SiC}$ high-temperature capability, this can lead to reduce the converter cooling requirements compared with $\mathrm{Si}$. By considering the heat sink reference temperature of $60^{\circ} \mathrm{C}$ and ambient temperature of $25^{\circ} \mathrm{C}$, the required heat sink thermal resistance for SiC-based converter is $0.35\left[{ }^{\circ} \mathrm{C} / \mathrm{W}\right]$ and $0.13\left[{ }^{\circ} \mathrm{C} / \mathrm{W}\right]$ for $\mathrm{Si}$ converter. To realize the required heat sink volume, a commercial heatsink (195AB) based on natural and forced air flow convection is selected. The heatsink thermal resistance for $\mathrm{SiC}$ devices is attained by a natural convection and by a forced air flow cooled system for Si devices. The approximate volumes of heatsinks are 1863.9 $\mathrm{cm}^{3}$ (without fan volume) for $\mathrm{Si}$ and $1342.2 \mathrm{~cm}^{3}$ for $\mathrm{SiC}$.

Furthermore, SiC devices have the merit of very good thermal stability over a wide range of operation, this leads to

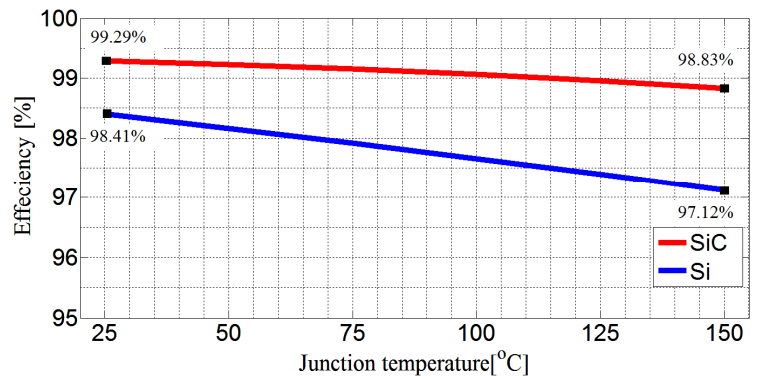

Fig. 14. Efficiency of $\mathrm{SiC}$ and $\mathrm{Si}$ devices vs temperature at maximum wind turbine output power and $16 \mathrm{kHz}$ switching frequency. 
increase the heatsink temperature without losing significant amount of power as shown in Fig. 14. Basically, the idea behind this is based on designing the heatsink at a reference temperature (i.e. $60^{\circ} \mathrm{C}$ ) in region II (region of interest) as shown in Fig. 15, where the wind distribution is relatively high, and then pushing the heatsink temperature from $60^{\circ} \mathrm{C}$ to $100^{\circ} \mathrm{C}$ at the maximum output power in region III where the wind distribution is relatively low. Moreover, by designing the heat sink at the wind output power of $8.5 \mathrm{~kW}$, efficiency of $99.3 \%$, heatsink temperature of $60^{\circ} \mathrm{C}$ and ambient temperature of $25^{\circ} \mathrm{C}$, the required thermal resistance is $0.63\left[{ }^{\circ} \mathrm{C} / \mathrm{W}\right]$ and the heatsink volume is $613.7 \mathrm{~cm}^{3}$ based on natural convection. Pushing the designed heatsink to operate at a temperature of $100^{\circ} \mathrm{C}$ at the maximum wind output power of $12 \mathrm{~kW}$ leads to reduce the heatsink volume by a factor of 2.2 and thus higher power density with just $0.2 \%$ reduction in the converter efficiency for a short time per a year.

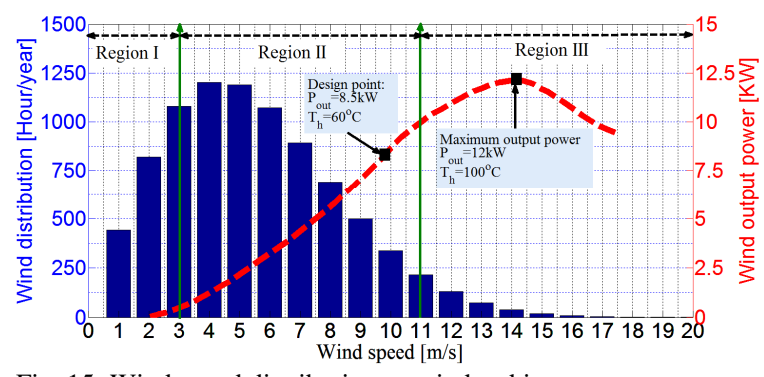

Fig. 15. Wind speed distribution vs wind turbine output power at different wind speeds.

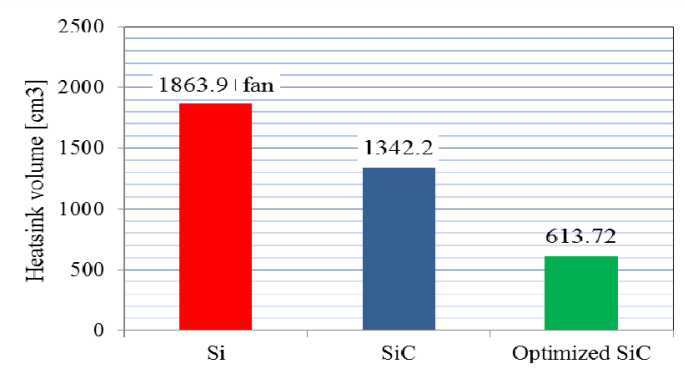

Fig. 16. . Heatsink volume for three different scenarios; Si, SiC and optimized $\mathrm{SiC}$.

\section{CONCLUSION}

This paper presented a performance benchmarking of SiIGBTs and SiC-MOSFETs based inverter in a small-scale wind turbine. In particular, the benchmarking analysis of the devices with $1200 \mathrm{~V}$ rating is performed based on $12 \mathrm{~kW} 2-\mathrm{L}$ Full Bridge grid-side inverter in $10 \mathrm{~kW}$ small wind turbine. $\mathrm{SiC}$ devices show high efficiency than Si devices especially in the region of high wind speed distribution which leads to saving energy losses up to $75 \%$ at switching frequency of $16 \mathrm{kHz}$. The reference switching frequency for SiC devices in this topology at this power level is determined around $48 \mathrm{kHz}$ based on the minimum converter volumes. Switching $\mathrm{SiC}$ devices at $48 \mathrm{kHz}$ allows reducing the output filter and DClink capacitor sizes by a factor of 2.1 and 2.8 respectively. Due to the higher temperature capability of SiC devices, the heatsink cooling requirements is reduced; the approximate heatsink volume reduction, not including cooling fans and accessories for $\mathrm{Si}$ devices, is about 1.4 times. In addition, combining a very good thermal stability of $\mathrm{SiC}$ devices and wind speed distribution profile allows increasing the heatsink temperature from $60^{\circ} \mathrm{C}$ to $100^{\circ} \mathrm{C}$, thus leading to reduce the heatsink volume by a factor of 2.2 with just $0.2 \%$ reduction in the converter efficiency for a short time per a year. Even the initial cost of SiC-MOSFET power module is higher than $\mathrm{Si}$ IGBT power module, the higher efficiency of SiC devices, its higher switching frequency, and its higher thermal capability and thermal stability have reduced the cost of small wind power inverter. The cost reduction is due to saving energy losses, reducing the output filter, DC-link capacitor and heatsink sizes and the operation cost as well as. As part of future work, Practical tests which support the proposed analysis will be investigated.

\section{ACKNOWLEDGMENT}

The authors gratefully acknowledge the support of the Ministry of Higher Education, Libya, in carrying out this research.

\section{REFERENCES}

[1] Rabkowski, J., D. Peftitsis, and H.P. Nee, Silicon carbide power transistors: A new era in power electronics is initiated. IEEE Industrial Electronics Magazine, 2012. 6(2): p. 17-26.

[2] Castellazzi, A., et al., SiC power MOSFETs performance, robustness and technology maturity. Microelectronics Reliability, 2016

[3] Sintamarean, C., et al. Wide-band gap devices in PV systems-opportunities and challenges. in Power Electronics Conference (IPEC-Hiroshima 2014-ECCE-ASIA), 2014 International. 2014. IEEE.

[4] DiMarino, C.M., R. Burgos, and B. Dushan, High-temperature silicon carbide: characterization of state-of-the-art silicon carbide power transistors. IEEE Industrial Electronics Magazine, 2015. 9(3): p. 19-30.

[5] Whaley, D.M., Low-cost small-scale wind power generation. 2009, The University of Adelaide, Australia.

[6] Chub, A., et al. Grid integration issues of PMSG-based residential wind turbines. in Electric Power Quality and Supply Reliability Conference (PQ), 2014. 2014. IEEE.

[7] Song, S.-H., S.-i. Kang, and N.-K. Hahm. Implementation and control of grid connected AC-DCAC power converter for variable speed wind energy conversion system. in Applied Power Electronics Conference and Exposition, 2003. APEC'03. Eighteenth Annual IEEE. 2003. IEEE.

[8] Blaabjerg, F., M. Liserre, and K. Ma, Power electronics converters for wind turbine systems. Industry Applications, IEEE Transactions on, 2012. 48(2): p. 708-719.

[9] Malinowski, M., et al., Optimized Energy-Conversion Systems for Small Wind Turbines: Renewable energy sources in modern distributed power generation systems. IEEE Power Electronics Magazine, 2015. 2(3): p. 16-30.

[10] Blinov, A., et al. Feasibility study of $\mathrm{Si}$ and SiC MOSFETs in high-gain DC/DC converter fo renewable energy applications. in Proc. of IECON. 2013

[11] Romlie, M.F., Impact of energy storage on the stability and transmission efficiency of a remote grid. 2014, University of Nottingham.

[12] Small wind turbines.[Online]. Available: http://www.small-windturbine.com

[13] Saridakis, S., E. Koutroulis, and F. Blaabjerg, Optimization of SiC-based H5 and Conergy-NPC transformerless PV inverters. Emerging and Selected Topics in Power Electronics, IEEE Journal of, 2015. 3(2): p. 555-567.

[14] Zhang, H. and L.M. Tolbert, Efficiency impact of silicon carbide power electronics for modern wind turbine full scale frequency converter. IEEE Transactions on Industrial Electronics, 2011. 58(1): p. 21-28.

[15] Selection Guide of SiC Schottky Diode in CCM PFC Applications. CPWR-AN05, REV, Cree, Inc., 4600 Silicon Drive, Durham, NC 27703.

[16] Nicolai, U. and A. Wintrich, Determining switching losses of SEMIKRON IGBT modules. SEMIKRON INTERNATIONAL GmbH, Nuremberg, Germany,Application Note AN 1403, 2014.

[17] Zhang, H., Electro-thermal modeling of SiC power electronic systems. Doctoral Dissertations, 2007: p. 201

[18] Drofenik, U., G. Laimer, and J.W. Kolar. Theoretical converter power density limits for forced convection cooling. in Proceedings of the International PCIM Europe 2005 Conference. 2005.

[19] Backlund, B., et al., Applying igbts. ABB, Lenzburg, Switzerland, Appl. Note 5SYA2053-01, 2007.

20] Seshasayee, N., Understanding thermal dissipation and design of a heatsink. Texas Instruments, Dallas, 2011.

[21] Kolar, J.W., et al. PWM converter power density barriers. in Power Conversion ConferenceNagoya, 2007. PCC'07. 2007. IEEE.

[22] Karanayil, B., V.G. Agelidis, and J. Pou. Evaluation of DC-link decoupling using electrolytic or polypropylene film capacitors in three-phase grid-connected photovoltaic inverters. in Industrial Electronics Society, IECON 2013-39th Annual Conference of the IEEE. 2013. IEEE.

[23] Wang, T.C., et al. Output filter design for a grid-interconnected three-phase inverter. in Power Electronics Specialist Conference, 2003. PESC'03. 2003 IEEE 34th Annual. 2003. IEEE.

[24] Caretto, L., Use of probability distribution functions for wind. Mechanical Engineering, 2010 483. 